\title{
Sulfated agarans from red seaweed Gracilaria cornea induce macrophages polarization to an antitumor M1 phenotype
}

Felipe Barros Teles ${ }^{1,2}$, Alexia Nathália Brígido Assef ${ }^{1}$, Renato Martins Andrade ${ }^{2}$, Vitória Virgínia Magalhães Soares ${ }^{2}$, Antônio Willame da Silva Alves², Roberto César Pereira LimaJúnior $^{1}$, Norma Maria Barros Benevides ${ }^{2 *}$, Diego Veras Wilke ${ }^{1^{*}}$

${ }^{1}$ Drug Research and Development Center, Department of Physiology and Pharmacology, Federal University of Ceará, Fortaleza, Ceará, Brazil

${ }^{2}$ Department of Biochemistry and Molecular Biology, Federal University of Ceará, Fortaleza, Ceará, Brazil

\section{*Corresponding authors:}

Diego Veras Wilke, Drug Research and Development Center, Department of Physiology and Pharmacology, Federal University of Ceará, Fortaleza, Ceará, Brazil - 60430-275. Telephone: +55 85 33668073. E-mail: diegowilke@gmail.com

Norma Maria Barros Benevides, Departament of Biochemistry and Molecular Biology, Federal University of Ceará, Fortaleza, Ceará, Brazil - 60451970. Telephone: +55 85 33669402. Fax: (85) 33669789. E-mail: normabbenevides@gmail.com

\begin{abstract}
Marine seaweeds are a rich source of sulfated polysaccharides with several biological activities, including antitumor effect. Some polysaccharides are also described to activate macrophages $(\mathrm{M} \phi \mathrm{s})$ to an antitumor M1-like phenotype. Here, we evaluated the capacity of sulfated galactans (SGs) extracts obtained from three seaweed species, Gracilaria cornea (Gc-E), Gracilaria birdiae (Gb-E), and Solieria filiformis (Sf-E), to activate the M $\phi$ s antitumor M1 phenotype. The nitric oxide production, MHCII, and CD86 (M1 markers) were evaluated to screening the bioactive SGs profile on murine M $\phi$ s (RAW 264.7 cells). The direct SGs antiproliferative effect was tested on melanoma B16-F10 cells. In another experimental setting, B16-F10 cells were incubated with a conditioned medium obtained from M $\phi$ s exposed to SGs. The three SGs tested induced NO release. Sf-E directly inhibited B16-F10 cells proliferation compared with the saline group, but Gc-E and Gb-E failed to inhibit cell proliferation. Notably, a conditioned medium $(\mathrm{CM})$ of $\mathrm{M} \phi \mathrm{s}$ incubated with Gc-E and Sf-E, but not of Gb-E, inhibited the proliferation of B16F10 cells. Gc-E also induced TNF- $\alpha$ release and increase of M1 markers such as iNOS, MHCII, and CD86. Therefore, Gc-E activates M $\phi$ s to M1 phenotype, which in turn releases a factor that inhibits B16-F10 proliferation.
\end{abstract}

Keywords: antitumor macrophages / macrophage activation / red seaweeds / sulfated polysaccharides. 


\section{Introduction}

Depending on the stimulus, monocytes/macrophages $(\mathrm{M} \phi \mathrm{s})$ undergo functional reprogramming and may exhibit a spectrum of different phenotypes. Interferon-gamma (IFN- $\gamma$ ) alone or associated with microbial lipopolysaccharides (LPS) polarizes M $\phi$ s for a classically activated M1 phenotype. On the other hand, IL-4 and IL-13 cytokines induce an alternatively activated M2 phenotype. Notably, M1-like phenotypes contribute to resistance against tumors, while the M2 M $\phi$ s trigger protumor mechanisms (Mantovani et al., 2014).

Sulfated polysaccharides (SPs) are biological macromolecules with a high negative charge (Bedini et al., 2017; Ruocco et al., 2016). In red seaweeds SPs are represented by the sulfated galactans (SGs) (Cian et al., 2015). Depending on the seaweed species, galactans exhibit structural differences and are divided into agaranas or carrageenans (Usov, 2011). Previous studies have demonstrated in vitro and in vivo activities of SGs obtained from red seaweeds species, including agaran-type from Gracilaria cornea and Gracilaria birdiae (Usov, 2011) and carrageenan-type from Solieria filiformis (Robledo \& Freire-Pleegrin, 2010). The biological activities include modulation of pain and inflammation (Coura et al., 2012), neuroprotective activity (Souza et al., 2016) anxiolytic (Monteiro et al., 2016), anticoagulant (Rodrigues et al., 2010), and antiviral effects (Morán-Santibañez et al., 2016). In this study we evaluated the activation and phenotype of murine macrophages RAW 264.7 incubated with SGs from red seaweeds G. cornea, G. birdiae and S. filiformis.

\section{Materials and methods}

\section{Reagents}

Dulbecco's modified Eagle medium (DMEM), fetal bovine serum (FBS), antibiotics (penicillin and streptomycin), and trypsin-EDTA were purchase from Gibco BRL Co. (Grand Island, NY, USA). Lipopolysaccharide from Escherichia coli (LPS), acetic acid, triton X-100, propidium iodide, doxorubicin, sulfanilamide, and NED reagents were obtained from Sigma Aldrich (St. Louis, MO, USA). Sodium nitrite $\left(\mathrm{NaNO}_{2}\right)$ was purchased from Dinâmica (Diadema, São Paulo, Brazil). TNF- $\alpha$ ELISA kit was purchased from R\&D Systems (Minneapolis, MN, USA).

\section{Isolation and characterization of sulfated galactans}

The seaweeds $G$. birdiae and S. filiformis were obtained during sampling procedures from an experimental culture located at $200 \mathrm{~m}$ from the coastal zone of Flecheiras Beach-Trairi, Ceará $\left(03^{\circ} 13^{\prime} 06\right.$ "S; $\left.039^{\circ} 16^{\prime} 47^{\prime \prime} \mathrm{W}\right)$. Graciliria cornea was collected in the intertidal zone at Flecheiras Beach. One voucher of each species (G. cornea, \#34739; G. birdiae, \#40781; and S. filiformis, 
\#35682) was deposited in the Herbarium Prisco Bezerra, Department of Biological Sciences, Federal University of Ceará, Brazil. The seaweeds were washed with distilled water, separated from epiphytes or other fouling organisms, and stored at $-20{ }^{\circ} \mathrm{C}$ until use. SGs derived from $G$. cornea (Gc-E) and S. filiformis (Sf-E) were obtained by protease digestion $\left(60^{\circ} \mathrm{C}\right.$ for six hours) in $100 \mathrm{mM}$ sodium acetate buffer (pH 5,0) containing $5 \mathrm{mM}$ EDTA and $5 \mathrm{mM}$ cysteine, with some modifications as previously described (Coura et al., 2012a; Araújo et al., 2011). SGs derived from G. birdiae (Gb-E) was obtained by non-enzymatic aqueous extraction at $85{ }^{\circ} \mathrm{C}$, according to Bezerra and Marinho-Soriano (Bezerra \& Marinho-Soriano, 2010), with some modifications. The use of these algae species was registered on the National System of Management of Genetic Heritage and Associated Traditional Knowledge (SisGen) under the number A93CDDO.

\section{Cell lines, culture procedures and treatments}

RAW 264.7, a murine macrophage cell line, and B16-F10, a murine metastatic melanoma cell line, were purchased from the Banco de Células do Rio de Janeiro (Rio de Janeiro, Brazil) and kept in the Laboratory of Marine Bioprospection and Biotechnology (LaBBMar) that has biosafety level 2 certified by National Technical Commission on Biosafety (CTNBio, Brazil) The cells were cultivated in DMEM containing $10 \%$ heat-inactivated FBS and 1\% penicillin/streptomycin at $37^{\circ} \mathrm{C}$ in a $5 \% \mathrm{CO} 2$ humidified atmosphere. The cells were regularly split to keep them into the exponential phase of growth. The Laboratory of Marine Bioprospection and Biotechnology at Drug Research and Development Center, Federal Univesrity of Ceará was granted by the National Technical Commission on Biosafety (CTNBio, Brazil) as a biosafety level 2 laboratory under the number 6.019/2018.

\section{NO analysis}

RAW 264.7 cells were exposed for $24 \mathrm{~h}$ to Gc-E $(10,100$, or $250 \mu \mathrm{g} / \mathrm{mL}$, Sf-E $(1,10$, or 100 $\mu \mathrm{g} / \mathrm{mL}$ ), Gb-E (10, 100, or $250 \mu \mathrm{g} / \mathrm{mL}$ ), saline (as negative control) or LPS (100ng/mL), as positive control. The nitric oxide (NO) levels formed in the supernatant of macrophages RAW 264.7 were indirectly measured by the Griess' test (Green et al., 1982). Briefly, $50 \mu$ of cell culture supernatants were mixed with $50 \mu \mathrm{l}$ of Griess reagent $(0.1 \%$ [wt/vol] naphthyl ethylenediamine and $1 \%[\mathrm{wt} / \mathrm{vol}]$ sulfanilamide in a $5 \%$ [vol/vol] phosphoric acid) in a $96-w e l l$ plate, incubated at room temperature for $10 \mathrm{~min}$. The absorbance was then measured with a microplate reader at $570 \mathrm{~nm}$. The absorbance values of the treated groups were interpolated from the linear regression performed with the data of the standard curve.

\section{Evaluation of antiproliferative effect in vitro}

The antiproliferative assay of samples was performed by SRB assay (Skehan et al., 1990). SRB method is used to determine cell density based on the total intracellular protein content measurement and does not depend on cellular metabolism. B16-F10 cells were either incubated 
for $48 \mathrm{~h}$ with saline, LPS $(100 \mathrm{ng} / \mathrm{mL})$, Gc-E, Sf-E, or Gb-E $(1-250 \mu \mathrm{g} / \mathrm{mL})$. In another experimental setting, RAW 264.7 cells were incubated for $24 \mathrm{~h}$ with the same compound concentrations mentioned above for obtaining the conditioned medium. B16-F10 cells were then incubated for $48 \mathrm{~h}$ with conditioned medium obtained from saline-treated macrophages (CM-Sal), LPS-treated M $\phi s$ (CM-LPS), or SG-treated macrophages (CM-Gc-E, CM-Sf-E, or CM-Gb-E). Therefore, we added $100 \mu \mathrm{L}$ of RAW 264.7 CM to an equal volume of the B16-F10 supernatant $(1: 1 \mathrm{v} / \mathrm{v})$, resulting in a dilution factor $=2$.

\section{Cytokine assays}

We measured TNF- $\alpha$ cytokine levels in supernatants of RAW 264.7 plated at $1.5 \times 10^{5}$ cells $/ \mathrm{mL}$ in 96 wells plate by ELISA, according to the manufacturers' instructions. The absorbance values of the treated groups were interpolated from the linear regression performed with the data of the standard curve.

\section{Analysis of cell immunostaining by flow cytometry}

We used murine FITC-conjugated anti-CD86 or murine PE-conjugated anti-MHCII antibodies from Thermo Fisher (Waltham, MA, USA) to stain the activation markers CD86 and MHCII, respectively. RAW 264.7 was incubated with the antibodies for 30 minutes at $4{ }^{\circ} \mathrm{C}$ in FACS buffer (PBS supplemented with 4\% FBS) and then washed with FACS buffer again. The cells were also fixed with paraformaldehyde $1 \%$ for 5 minutes and permeabilized with Triton $0.1 \%$ for 5 minutes for iNOS labeling. Then, cells were incubated with murine Alexa Fluor 488-conjugated antibody for 30 minutes at $4{ }^{\circ} \mathrm{C}$ in FACS buffer and washed with FACS buffer again. We used flow cytometry (model FACSVerse, BD Biosciences, San Jose, USA) for data acquisition and the FlowJo software (San Jose, CA, USA) for the analysis of the median fluorescence intensity values (MFI) of iNOS, MHCII, and CD86 expression, which were normalized by the mean of negative control MFI. The percentage of double-labeled cells was used to show the population of cells expressing MHCII and CD86 simultaneously.

\section{Statistical analysis}

The data represents the mean $\pm \mathrm{SD}$ of three technical and biological replicates. We used one-way analysis of variance (ANOVA) followed by Dunnett or Tukey's multiple comparison tests to detect the statistical difference between the groups. $P<0.05$ was considered statistically significant. Statistical analysis was performed using the GraphPad Prism 6.0 software (San Diego, CA, USA). 


\section{Results and Discussion}

\section{Sulfated galactans extracts stimulate RAW 264.7 to produce nitric oxide (NO)}

All SGs extracts stimulated NO release by Mфs (Fig. 1A). While Gc-E stimulation was observed at all concentrations, Sf-E predominantly induced NO release at lower concentrations (1 and 10 $\mu \mathrm{g} / \mathrm{mL}$ ) and $\mathrm{Gb}-\mathrm{E}$ at the higher concentration $(250 \mu \mathrm{g} / \mathrm{mL}$ ) (Fig. 1A). NO is a crucial component of the host immune response against various pathogens such parasites, bacteria, and viruses (Bogdan et al., 2000; Xue et al., 2018). NO production is considered a classical M1 phenotype marker (Zhu et al., 2014). SGs from brown seaweed Cystoseria indica induced the release of NO from RAW 264.7 by activating the Toll-like 4 receptor (TLR4)/NF- $\mathrm{B}$ and MAPKs signaling pathways (Bahramzadeh et al., 2019). Another sulfated polysaccharide from seaweed, Nizamuddinia zanardinii, similarly activated RAW 264.7 to secrete NO, TNF- $\alpha$, and other cytokines (Tabarsa et al., 2020). Additional in vitro studies further reported that galactans also activate M $\phi$ s to M1-like phenotype. The mechanisms seem to involve TLR4- and autophagydriven macrophage pro-inflammatory phenotype, as demonstrated by the hetero-galactan from fungi Flammulina velutipes (Y. Meng et al., 2018). The consistency of such mechanism seems to be shared by other galactans, including those obtained from Panax ginseng flowers or fruiting bodies of Cantharellus cibarius, which activate RAW 264.7 M $\phi$ s to increase phagocytosis and the release of NO, TNF- $\alpha$, IL-6, IFN- $\gamma$, and IL-1 $\beta$ (Cui et al., 2020; Yang et al., 2019).

\section{Antiproliferative effect of sulfated galactans extracts against B16-F10 cells}

SGs are known for their antiproliferative effect on tumor cells (Khotimchenko et al., 2020). Accordingly, Sf-E demonstrated a marked antiproliferative effect on B16-F10 cells. Conversely, Gc-E and Gb-E failed to inhibit tumor cell growth (Fig. 1B). Remarkably, SGs of marine origin display low toxicity, which allows its widespread use as food compounds (Fedorov et al., 2013). Such findings contrast with the well-described in vitro antiproliferative activity of carrageenans. The iota-carrageenan extracted from red seaweed Laurencia papillosa inhibits cell proliferation of adenocarcinoma cell line by inducing apoptosis (Murad et al., 2015). The same is also described to the kappa(k)-carrageenan from red seaweed Hypneia musciformis, which reduces neuroblastoma cell-line proliferation (Souza et al., 2018). The mechanism might involve the phase-specific cell cycle arrest, as reported to $\operatorname{kappa}(\kappa)$ and lambda $(\lambda)$-carrageenans on HeLa cells (Prasedya et al., 2016). 
A

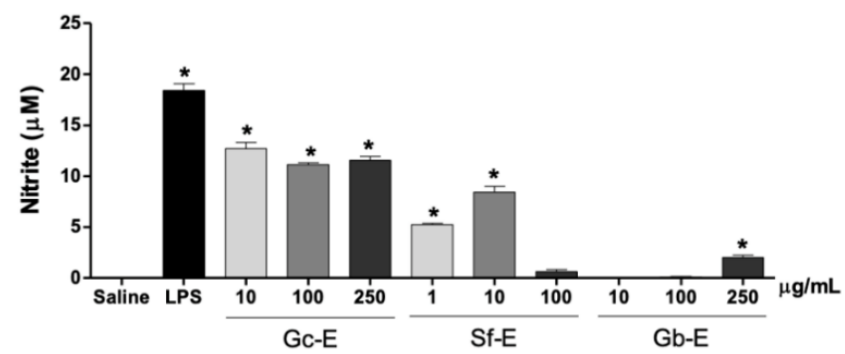

B
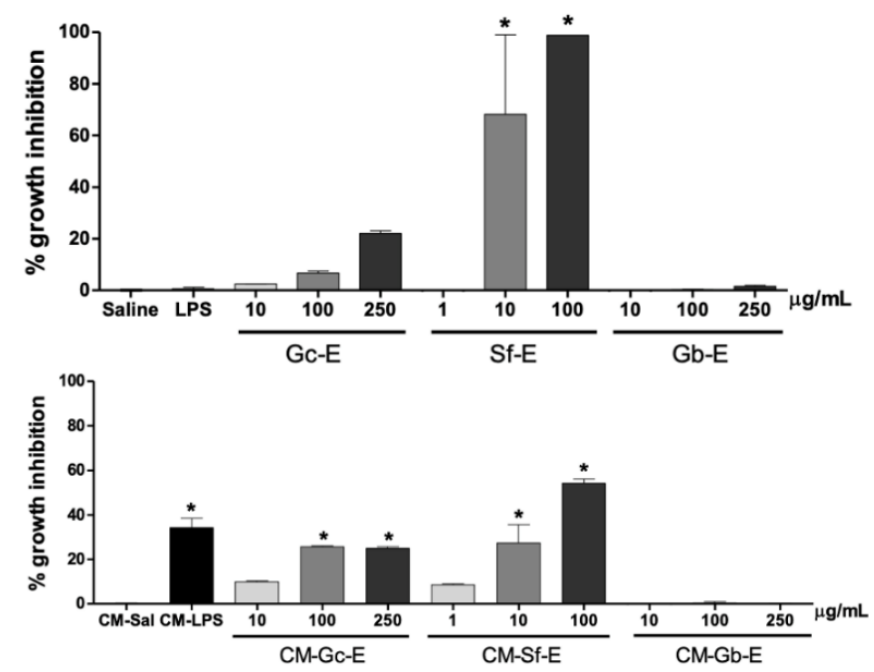

Figure 1. Bioactive profile of sulfated galactans extracts. A, Nitrite levels produced by macrophages (RAW 264.7 cell line) evaluated by Griess assay. RAW 264.7 cells were exposed to saline as a negative control, E. coli lipopolysaccharide (LPS) at $100 \mathrm{ng} / \mathrm{mL}$ as positive control and increasing concentrations of sulfated polysaccharides extracted from Gracilaria cornea (GcE), Solieria filiformis (Sf-E), or Gracilaria birdiae (Gb-E) for 24h. B, Antiproliferative effect of Gc-E, Sf-E, and Gb-E against the murine metastatic melanoma cell line (B16-F10) following a $48 \mathrm{~h}$ exposure evaluated by SRB assay. C, Antiproliferative effect of macrophage-conditioned medium (CM) obtained after a 24-h RAW 264.7 cell incubation with Gc-E, Sf-E, or Gb-E. B16F10 cells were exposed to CM for $48 \mathrm{~h}$. Differences between data normalized to percentage of cell growth inhibition ( $\mathrm{B}$ and $\mathrm{C}$ ) of negative control versus other groups were determined by the analysis of variance (ANOVA) followed by Dunnett's post-test. *p<0.05.

\section{Conditioned medium obtained from RAW 264.7 cells stimulated with sulfated galactans extracts inhibits the proliferation of B16-F10 cells}

The conditioned medium (CM) obtained from MФs exposed to Gc-E (CM-Gc-E) or Sf-E (CMSf-E), but not CM-Gb-E, inhibited B16-F10 cell growth. The effective concentrations varied from 10 to $250 \mu \mathrm{g} / \mathrm{mL}$ depending on the extract (Fig. 1C). Engström and colleagues demonstrated that conditioned media of human macrophages (differentiated from THP-1 monocytes) polarized to an M1-phenotype by LPS and interferon $\gamma$ inhibits the proliferation of colorectal adenocarcinoma cell lines (Engström et al., 2014). A comparable experimental approach also effectively inhibited the proliferation of a breast cancer cell line by macrophages derived from bone marrow (ReyGiraud et al., 2012). Notably, as far as we know, this is the first report on the antitumor profile of MФs activated by polysaccharides from natural sources. It is also worth to highlight two advantages conferred by this model used with M $\phi$ s RAW 264.7 cell line instead of monocytes or 
bone marrow. Firstly, it was the overall shorter time to perform the experiments due to the lack of monocyte differentiation into macrophage step, and second, in the case of bone marrow as source of cells, it was the absence of animal ethical issues.

\section{Gc-E activates RAW 264.7 to produce TNF- $\alpha$}

Gc-E exhibited the most suitable bioactive profile among the tested SGs. It showed mild direct cytotoxicity against tumor cells, stimulated NO production by $\mathrm{M} \phi \mathrm{s}$, and stimulated the macrophages to release factors capable of inhibiting B16-F10 growth. Remarkably, Gc-E stimulated TNF- $\alpha$ production by RAW 264.7 at 100 and $250 \mu \mathrm{g} / \mathrm{mL}$ (Fig. 2). TNF- $\alpha$ is a cytokine produced by some immune cells, like $\mathrm{M} \phi \mathrm{s}$, during inflammation, infection, or injury and is also considered an M1 marker (Rock, C.S. \& Lowry, S.F., 1994; Murray, P. et al., 2014). During the 70s, Carswell and collaborators demonstrated that TNF- $\alpha$ induces tumor regression (Carswell, E.A., 1975). To test B16-F10 responsiveness to TNF- $\alpha$, we incubated these tumor cells with different concentrations of this cytokine (up to $1 \mathrm{ng} / \mathrm{mL}$ ) to assess the inhibition of cell growth. Intriguingly, there was no cell growth inhibition at any of the concentrations tested (data not shown). Therefore, the antiproliferative factors released by $M \phi s$ in the CM-Gc-E merit to be determined in a further study.

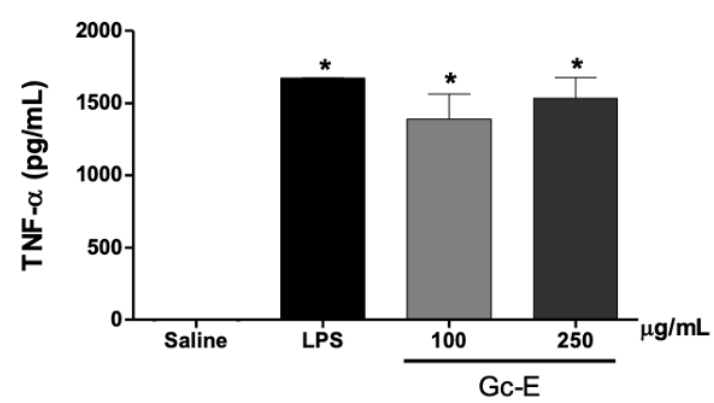

Figure 2. Sulfated agarans extract from Gracilaria cornea (Gc-E) induce TNF- $\alpha$ releasing by macrophages. RAW 264.7 cells were exposed to saline as a negative control, E. coli lipopolysaccharide (LPS, $100 \mathrm{ng} / \mathrm{mL}$ ) as a positive control, or Gc-E (100 or $250 \mu \mathrm{g} / \mathrm{mL}$ ). Differences between negative control versus the other groups were determined by the analysis of variance (ANOVA) followed by Dunnett's post-test. * $<<0.05$.

\section{Gc-E increases the expression of macrophage activation markers}

The inducible nitric oxide synthase (iNOS) is an isoform of the enzyme synthesizing NO using L-arginine as a precursor (Hevel et al., 1991; Marletta et al., 1988). The Griess assay detects nitrite levels as indirect evidence of NO production. Here, RAW 264.7 cells incubated with Gc-E (250 $\mu \mathrm{g} / \mathrm{mL}$ ) showed a five-fold increase in iNOS expression versus the saline group (Fig. 3A-B), which is in line with the nitrite levels (Fig. 1A), suggesting the involvement of NO in the Gc-E mechanism of action. Additionally, Gc-E at $250 \mu \mathrm{g} / \mathrm{mL}$ increased MHC class II and CD86 expressions by 3 -fold and 1.5-fold, respectively, compared with the control group (Fig. 3 C-H). Macrophages and other immune cells express MHC class II molecules to present antigens for 
CD4+ effector T cells (Rock, K.L. et al., 2016), a process that involves CD86 co-stimulatory surface molecules (Porta, C. et al., 2015). Noteworthy, all these molecules are important markers of M1 macrophage activation (Xue et al., 2018).

Gupta and cols. demonstrated that polysaccharides derived from Tinospora cordifolia induce the secretion of pro-inflammatory cytokines, such as TNF- $\alpha$, IL-1 $\beta$, IL- 6 , IL-12, and IFN- $\gamma$, by RAW 264.7. Moreover, NO levels are also enhanced along with the up-regulation of iNOS and surface MHC-II and CD-86 expression in murine M $\phi$ s post-treatment with $T$. cordifolia polysaccharides (Gupta et al., 2017).

A

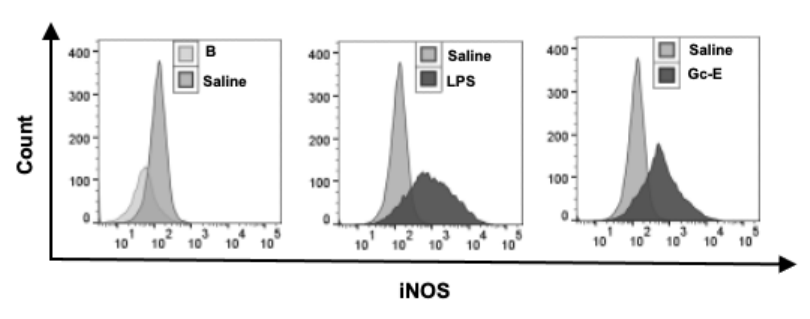

C

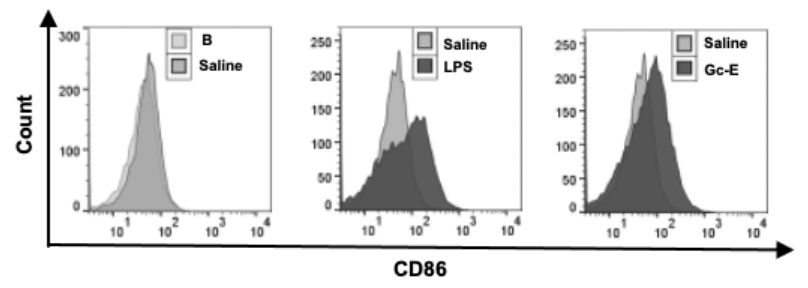

$\mathbf{E}$

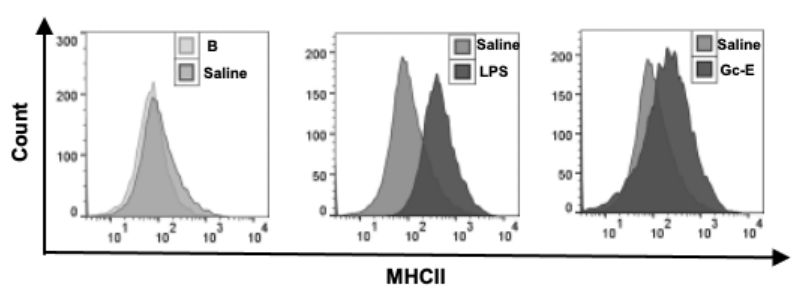

G

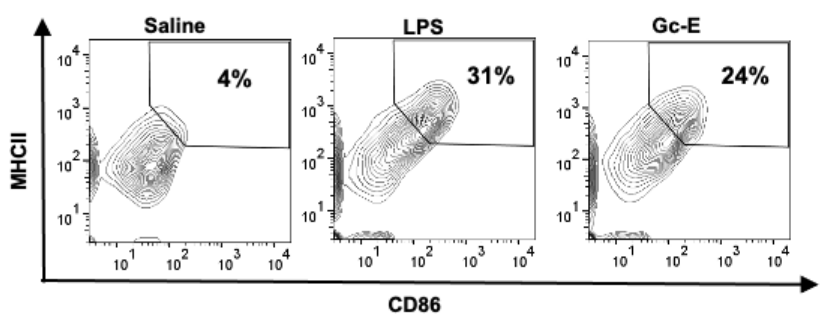

B

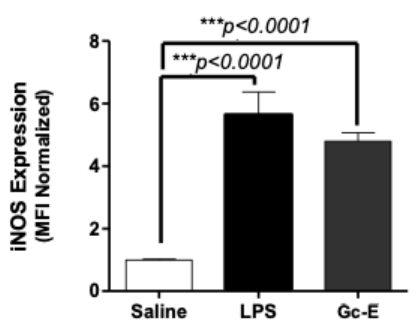

D

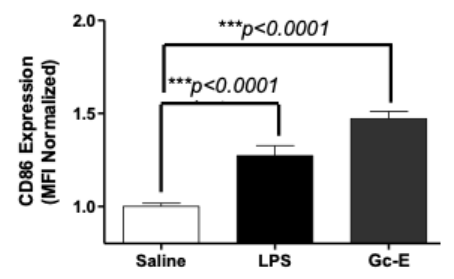

$\mathbf{F}$

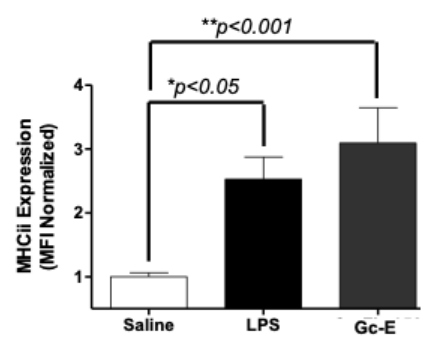

H

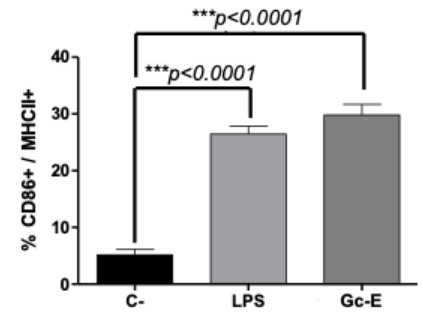

Figure. 3. Sulfated agaran extract from Gracilaria cornea (Gc-E) induces a macrophage (RAW 264.7) M1 phenotype. Nitrite oxide production was evaluated by iNOS expression on RAW 264.7 cells by flow cytometry (A and B). Expression of CD86 and MHCII was evaluated on RAW 264.7 cells by flow cytometry (C-H). RAW 264.7 cells were incubated for $24 \mathrm{~h}$ with saline as a negative control, E. coli lipopolysaccharide (LPS, $100 \mathrm{ng} / \mathrm{mL}$ ) as a positive control, and Gc-E at $250 \mu \mathrm{g} / \mathrm{mL}$. Flow cytometry histograms are depicted on A, D, and E. Median fluorescence intensity (MFI) data are depicted on B, D, and F, as normalized values. Percentage of CD86+/MHCII+ cells are depicted on $\mathrm{G}$ and $\mathrm{H}$. Ten thousand events, excluding debris and doublets, were acquired on flow cytometry experiments. Unstained cells were used as blank (B) 
as basal antibody background reference. The mean differences between the negative control versus other groups were compared by analysis of variance (ANOVA) followed by Dunnett's post-test. ${ }^{*} \mathrm{p}<0.05$. Results are representative of three independent experiments, each one performed in triplicate.

Meng and cols. showed that polysaccharide from a novel fungal strain isolated from the species Cordyceps sinensis promotes proliferation of RAW 264.7, increases phagocytic activity, releases NO, and increases the secretion of IL-6, Il-1 $\alpha$, IL-10, and TNF- $\alpha$, and chemokines, such as MIP$1 \alpha$ and CXCL10 (IP-10). Both cytokines and chemokines are essential mediators released during the inflammatory processes. Eventually, the authors found enhanced expression of MHC II and CD86 in RAW 264.7 pre-treated with C. sinensis polysaccharides (L. Z. Meng et al., 2014). Remarkably, SPs from red seaweed Champia feldmmanii does not exhibit significant in vitro cytotoxicity but an in vivo antitumor effect. It might be explained by immunostimulating activity (Lins et al., 2009). Paclitaxel, a highly cytotoxic chemotherapeutic drug used to treat several cancers, also reduces tumor growth by reprogramming $\mathrm{M} \phi \mathrm{s}$ to an $\mathrm{M} 1$ phenotype, a process mediated by Toll-like receptor-4 (Wanderley et al., 2018). Altogether, our results suggest that the polysaccharides from $G$. cornea are promising immunomodulatory agents. Additionally, Gc-E may exert in vivo antitumor inhibition by modulating the tumor microenvironment targeting $\mathrm{M} \phi \mathrm{s}$. Further studies are ongoing to address the immunostimulatory and in vivo antitumor effects of Gc-E.

\section{Conclusions}

In summary, Gc-E induced macrophage activation to an M1 phenotype and depict antiproliferative in vitro effect on tumor cells. This antiproliferative effect of CM-GcE was not associated with direct cytotoxicity. Further studies are needed to understand the mechanisms involved in the activation of $\mathrm{M} \phi \mathrm{s}$ by SGs and which factors are released by these cells in the conditioned medium to exert the GcE antiproliferative effect against B16-F10 cells.

\section{Acknowledgements}

This work was supported by Coordenação de Aperfeiçoamento de Pessoal de Nível Superior Brasil (CAPES) for scholarships and financial support (Ciências do Mar II CAPES finance code $\mathrm{n}^{\mathrm{o}} 23038.001422 / 2014-84$ ) and National Institute of Science and Technology on Biodiversity and Natural Products (INCT BioNat-CNPq/FAPESP, Finance code n ${ }^{\circ} 465637 / 2014-0$ ). The authors also would like to thank the Multi-User Facility of Drug Research and Development Center of Federal University of Ceará for technical support.

\section{Conflict of interest}

The authors declare no conflict of interest. 


\section{References}

Bahramzadeh S, Tabarsa M, You S, Li C, Bita S. 2019. Purification, structural analysis and mechanism of murine macrophage cell activation by sulfated polysaccharides from Cystoseira indica. Carbohydr. Polym. 205: 261-270.

Bedini E, Laezza A, Parrilli M, Iadonisi A. 2017. A review of chemical methods for the selective sulfation and desulfation of polysaccharides. Carbohydr. Polym. 174: 12241239.

Bezerra AF, Marinho-Soriano E. 2010. Cultivation of the red seaweed Gracilaria birdiae (Gracilariales, Rhodophyta) in tropical waters of northeast Brazil. Biomass Bioenergy. 34: 1813-1817.

Bogdan C, Röllinghoff M, Diefenbach A. 2000. The role of nitric oxide in innate immunity. Immunol. Rev. 173: 17-26.

Carswell E, Old L, Kassel R. Greem S, Fiore N, Williamson B. 1975. An endotoxin-induced serum factor that causes necrosis of tumors. Proc. Natl. Acad. Sci. U.S.A.. 72: 3666-3670.

Cian R, Drago SR, de Medina FS, Martínez-Augustin O. 2015. Proteins and carbohydrates from red seaweeds: Evidence for beneficial effects on gut function and microbiota. Mar. Drugs. 13: 5358-5383.

Coura CO, de Araújo IWF, Vanderlei ESO, Rodrigues JAG, Quinderé ALG, Fontes BP, de Queiroz INL, de Menezes DB, Bezerra MM, e Silva AAR, Chaves HV, Jorge RJB, Evangelista JSAM, Benevides NMB. 2012. Antinociceptive and Anti-Inflammatory Activities of Sulphated Polysaccharides from the Red Seaweed Gracilaria cornea. Basic Clin. Pharmacol. Toxicol. 110: 335-341.

Cui L, Chen L, Yang G, Li Y, Qiao Z, Liu, Y, Meng Y, Zhou Y, Sun L. 2020. Structural characterization and immunomodulatory activity of a heterogalactan from Panax ginseng flowers. Food Res. Int. 140: 109859.

De Araújo IWF, Vanderlei ESO, Rodrigues JAG, Coura CO, Quinderé ALG, Fontes BP, Queiroz INL, Jorge RJB, Bezerra MM, e Silva AAR, Chaves HV, Monteiro HSA, de Paula RCM, Benevides NMB. 2011. Effects of a sulfated polysaccharide isolated from the red seaweed Solieria filiformis on models of nociception and inflammation. Carbohydr. Polym. 86: 1207-1215.

Engström A, Erlandsson A, Delbro D, Wijkander J. 2014. Conditioned media from macrophages of M1, but not M2 phenotype, inhibit the proliferation of the colon cancer cell lines HT-29 and CACO-2. Int. J. Oncol. 44: 385-392.

Fedorov SN, Ermakova SP, Zvyagintseva TN, Stonik VA. 2013. Anticancer and cancer preventive properties of marine polysaccharides: Some results and prospects. Mar. Drugs. 11: 4876-4901. 
Gupta PK, Rajan MGR, Kulkarni S. 2017. Activation of murine macrophages by G1-4A, a polysaccharide from Tinospora cordifolia, in TLR4/MyD88 dependent manner. Int. Immunopharmacol. 50: 168-177.

Hevel, JM, White KA, Marletta MA. 1991. Purification of the inducible murine macrophage nitric oxide synthase: Identification as a flavoprotein. J. Biol. Chem., 266: 22789-22791.

Khotimcehnko M, Tiest V, Kalitnik A, Begun M, Khotimcehnko R, Leoteva E, Bryukhovetskiy, Khotimcehnko Y. 2020. Antitumor potential of carrageenans from marine red algae. Carbohydr. Polym. 246: 116568

Lins KOAL, Bezerra DP, Alves APNN, Alencar NMN, Lima MW, Torres VM, Farias WRL, Pessoa C, De Moraes MO, Costa-Lotufo LV. 2009. Antitumor properties of a sulfated polysaccharide from the red seaweed Champia feldmannii (Diaz-Pifferer). J. Appl. Toxicol. 29: 20-26.

Mantovani A, Vecchi A, Allavena P. 2014. Pharmacological modulation of monocytes and macrophages. Curr. Opin. Pharmacol. 17: 38-44.

Marletta MA, Yoon PS, Iyengar R, Leaf CD, Wishnok JS. 1988. Macrophage Oxidation of LArginine to Nitrite and Nitrate: Nitric Oxide Is an Intermediate. Biochemistry. 27: 87068711.

Meng LZ, Feng K, Wang LY, Cheong KL, Nie H, Zhao J, Li SP. 2014. Activation of mouse macrophages and dendritic cells induced by polysaccharides from a novel Cordyceps sinensis fungus UM01. J. Funct. Foods. 9: 242-253.

Meng Y, Yan J, Yang G, Han Z, Tai G, Cheng H, Zhou Y. 2018. Structural characterization and macrophage activation of a hetero-galactan isolated from Flammulina velutipes. Carbohydr. Polym. 183: 207-218.

Monteiro VS, Teles FB, Coura CO, Souza RB, Lima CN de C, Costa DV da S, Junior ERH, Escudeiro, S de S, Chaves EMC, Vasconcelos SMM, Benevides NMB. 2016. Involvement of the GABAergic system in the anxiolytic effect of sulfated polysaccharides from the red seaweed Gracilaria cornea. J. Appl. Phycol. 28: 1997-2004.

Morán-Santibañez K, Cruz-Suárez LE, Ricque-Marie D, Robledo D, Freile-Pelegrín Y, PeñaHernández MA, Rodríguez-Padilla C, Trejo-Avila LM. 2016. Synergistic effects of sulfated polysaccharides from Mexican seaweeds against measles virus. Biomed Res. Int. 2016: [special issue].

Murad H, Ghannam A, Al-Ktaifani M, Abbas A, Hawat M. 2015. Algal sulfated carrageenan inhibits proliferation of MDA-MB-231 cells via apoptosis regulatory genes. Mol. Med. Rep. 11: 2153-2158.

Murray PJ, Allen JE, Biswas SK, Fisher EA, Gilroy DW, Goerdt S, Gordon S, Hamilton JA, Ivashkiv LB, Lawrence T, et al. 2014. Macrophage Activation and Polarization: Nomenclature and Experimental Guidelines. Immunity. 41: 14-20. 
Porta C, Riboldi E, Ippolito A, Sica A. 2015. Molecular and epigenetic basis of macrophage polarized activation. Semin. Immunol. 27: 237-248.

Prasedya ES, Miyake M, Kobayashi D, Hazama A. 2016. Carrageenan delays cell cycle progression in human cancer cells in vitro demonstrated by FUCCI imaging. BMC Complement Altern Med. 16: 270.

Rey-Giraud F, Hafner M, Ries CH. 2012. In vitro generation of monocyte-derived macrophages under serum-free conditions improves their tumor promoting functions. PLoS ONE, 7: e42656.

Robledo D, Freile-Pelegrín Y. 2011. Prospects for the cultivation of economically important carrageenophytes in Southeast Mexico. J. Appl. Phycol. 23: 415-419

Rock KL, Reits E, Neefjes J. 2016. Present Yourself! By MHC Class I and MHC Class II Molecules. Physiol. Behav. 176: 139-148.

Rodrigues JAG, De Araújo IWF, de Paula GA, Bessa EF, Lima T de B, Benevides NMB. 2010. Isolamento, fracionamento e atividade anticoagulante de iota-carragenanas da Solieria filiformis. Cienc. Rural 40: 2310-2316. https://doi.org/10.1590/S010384782010001100010

Ruocco N, Costantini S, Guariniello S, Costantini, M. 2016. Polysaccharides from the Marine Environment with Pharmacological, Cosmeceutical and Nutraceutical Potential. Molecules. 21: 551.

Souza RB, Frota AF, Silva J, Alves C, Neugebauer AZ, Pinteus S, Rodrigues JAG, Cordeiro EMS, de Almeida RR, Pedrosa R, Benevides NMB. 2018. In vitro activities of kappacarrageenan isolated from red marine alga Hypnea musciformis: Antimicrobial, anticancer and neuroprotective potential. Int. J. Biol. Macromol. 112: 1248-1256.

Skehan P, Storeng R, Scudiero D, Monks A, McMahon J, Vistica D, Warren JT, Bokesch H, Kenney S, Boyd MR. 1990. New colorimetric cytotoxicity assay for anti- cancer-drug screening. J. Natl. Cancer Inst. 82: 1107.

Souza RB, Frota AF, Sousa RS, Cezario NA, Santos TB, Souza LMF, Coura CO, Monteiro VS, Filho GC, Vasconcelos SMM, da Cunha RMS, Aguiar LMV, Benevides, NMB. 2016. Neuroprotective Effects of Sulphated Agaran from Marine Alga Gracilaria cornea in Rat 6-Hydroxydopamine Parkinson's Disease Model: Behavioural, Neurochemical and Transcriptional Alterations. Basic Clin. Pharmacol. Toxicol. 120: 159-170.

Tabarsa M, Dabaghian EH, You SG, Yelithao K, Cao RA, Rezaei M, Alboofetileh M, Bita S. 2020. The activation of NF- $\mathrm{kB}$ and MAPKs signaling pathways of RAW264.7 murine macrophages and natural killer cells by fucoidan from Nizamuddinia zanardinii. Int. J. Biol. Macromol. 148: 56-67.

Usov AI. 2011. Polysaccharides of the red algae. Adv. Carbohydr. Chem. Biochem. 65: 115- 
217.

Wanderley CW, Colón DF, Luiz JPM, Oliveira FF, Viacava PR, Leite CA, Pereira JA, Silva CM, Silva CR, Silva, RL, et al. 2018. Paclitaxel reduces tumor growth by reprogramming tumor-associated macrophages to an M1 profile in a TLR4-dependent manner. Cancer Res. 78: 5891-5900.

Xue Q, Yan Y, Zhang R, Xiong H. 2018. Regulation of iNOS on immune cells and its role in diseases. Int. J. Mol. Sci. 19: 3805.

Yang G, Qu Y, Meng Y, Wang Y, Song C, Cheng H, Li X, Sun L, Zhou Y. 2019. A novel linear 3-O-methylated galactan isolated from Cantharellus cibarius activates macrophages. Carbohydr. Polym. 214: 34-43.

Zhu L, Zhao Q, Yang T, Ding W, Zhao Y. 2015. Cellular metabolism and macrophage functional polarization. Int. Rev. Immunol. 34: 82-100. 